\title{
PODE-SE VIVER SEM NORTE? A DISCIPLINA DO ESPAÇO
}

\author{
Rosilene Beatriz Machado \\ Universidade Federal de Santa Catarina - UFSC - Brasil \\ Cláudia Regina Flores \\ Universidade Federal de Santa Catarina - UFSC - Brasil
}

(aceito para publicação em maio de 2018)

\begin{abstract}
Resumo
Este artigo tem por objetivo apresentar uma análise de como práticas de desenho e matemática foram (re)significadas nos domínios da cartografia, analisando-as-as em sua historicidade. Situamo-nos, dessa forma, em seu campo de emergência, buscando os rastros históricos dos conteúdos escolares da disciplina de desenho, em suas relações com a matemática. $\mathrm{O}$ intuito é analisar, enfim, como tais práticas deram-se a ver e dizer de maneiras distintas das que experimentavam até então, em uma investigação que se pauta não pela procura das causas de uma súbita mudança, mas pelo estabelecimento do sistema de transformações em que ela consiste.
\end{abstract}

Palavras-chave: Matemática, História, Desenho, Cartografia.

\section{[CAN ONE LIVE WITHOUT THE NORTH? THE DISCIPLINE OF SPACE]}

\begin{abstract}
This article aims to present an analysis of how drawing and mathematical practices were (re)signified in the areas of cartography, perceiving them in their historicity. We find ourselves, in this way, in its field of emergency, searching for the historical traces of the school contents of the discipline of drawing, in its relations with mathematics. The intention is to see, finally, how these practices came to be seen and to be said in different ways from those that they had experienced until then, in an investigation that is guided not by the search of the causes of a sudden change, but by the establishment of the system of transformations in which it consists.
\end{abstract}

Keywords: Mathematics, History, Drawing, Cartography.

RBHM, Vol. 17, n 34, p. 49-71, 2017 


\section{Dos norteamentos}

Nossa movimentação transversal de pesquisa em história(s) (da matemática, do desenho, da ciência, da educação, da educação matemática, etc.) têm-se balizado, especialmente, pelo questionamento de como domínios de saber puderam formar-se a partir de práticas sociais. Dito de outra forma, temos buscado, em nossas investigações, compreender como práticas "podem chegar a engendrar domínios de saber que não somente fazem aparecer novos objetos, novos conceitos, novas técnicas, mas também fazem nascer formas totalmente novas de sujeitos e sujeitos de conhecimento" (FOUCAULT, 2013, p. 18). O que temos perguntado, mais especificamente, é como determinadas práticas sociais teriam adquirido o estatuto de conteúdo escolar a partir do pressuposto (sem presunção de prova, mas apenas de alargamento de potencialidades) de que investigar práticas sociais em âmbitos não escolares pode melhor esclarecer as características da vida escolar dessas mesmas práticas ${ }^{1}$. Considerando-se, assim, que práticas de disciplinarização cultural (como as escolares) só são possíveis a partir de práticas de produção cultural (MIGUEL, 2010) ${ }^{2}$.

Nesse sentido, a partir da problematização: como práticas sociais de desenhar teriam adquirido o estatuto de conteúdo escolar?, nosso propósito no presente texto é apresentar uma análise de como práticas de desenho e matemática foram (re)significadas nos domínios da cartografia, percebendo-as em sua historicidade. Problematização que persegue, portanto, os rastros da natureza histórica dos conteúdos escolares da disciplina de desenho $^{3}$, situando-nos em seu campo de emergência. Que busca perceber, enfim, como tais práticas deram-se a ver e dizer de maneiras distintas das que experimentavam até então; analisando o desenrolar desse emaranhado, ressalte-se, não pela procura das causas de uma súbita 'mudança', mas sim pelo estabelecimento do sistema de transformações em que ela consiste ${ }^{4}$.

Para tanto, é importante destacar que, assim como em relação à matemática, estão nas Academias Militares e na 'arte da guerra' as 'origens' ${ }^{5}$ do desenho enquanto disciplina escolar'. A partir do século XIV, novas configurações de guerra foram postas em ação por conta do aparecimento das primeiras armas de fogo e de sua rápida evolução e aperfeiçoamento. A artilharia evoluiu para o canhão nos séculos seguintes e a partir do século XVII influiu fortemente sobre as formas de se construir fortificações:

\footnotetext{
${ }^{1}$ Para uma maior compreensão acerca das perspectivas conceituais sob as quais nossos trabalhos em história(s) têm sido produzidos ver: Flores (2007); Machado (2016); Machado \& Flores (2016); Machado \& Flores (2016a).

${ }^{2}$ Cumpre dizer que há casos bastante específicos e pontuais de conteúdos ou disciplinas que emergem e disciplinarizam-se no interior da própria escola, tal como é o caso, por exemplo, da 'gramática francesa' analisado por Chervel (1990).

${ }^{3}$ Importante destacar que o problema de pesquisa colocado trata do desenho enquanto disciplina escolar, ou seja, não se pretende uma história de alguma modalidade específica de desenho (tal como desenho geométrico, perspectivo, descritivo, técnico, arquitetônico, industrial, artístico, dentre tantos outros).

${ }^{4}$ As análises aqui apresentadas são oriundas do trabalho de tese intitulado: Cartografia, Saber, Poder: Da emergência do desenho como disciplina escolar. Ver: Machado (2016).

${ }^{5}$ Não no sentido de um começo absoluto, mas de um complexo campo de elaboração e validade em que se dá a constituição de um saber.

${ }^{6}$ Esta compreensão quanto à matemática é defendida, por exemplo, por autores tais como o historiador francês Bruno Belhoste e, especificamente no Brasil, por Valente (2007), que apontam uma estreita ligação entre guerra e educação matemática, no sentido de que as matemáticas escolares têm nas Academias Militares suas origens.
} 
"As grandes muralhas se abaixam; muda o traçado das obras, para obtenção de fogos cruzados; modificam-se os métodos de construção, para proteção das guarnições; criam-se obstáculos para impedir a aproximação. Tudo enfim, é alterado e aperfeiçoado. Fica constituída, assim, uma forma inteiramente nova de arquitetura das fortificações." (VALENTE, 2007, p. 40)

Essa nova forma de fortificação criou a necessidade de uma mão-de-obra especializada, fazendo surgir pela Europa as Aulas de Artilharia e Fortificação. Estas, por sua vez, passaram a formar um novo profissional: o engenheiro militar, cujo núcleo de seu ofício era dado por "estratégias de ataque, por meio dos aparelhos de guerra de artilharia e a defesa por meio das fortificações concebidas para resistir ao inimigo" (Ibidem, p. 41). Em função do acelerado desenvolvimento dos canhões, novas questões e problemas emergiram em torno da necessidade de defesa, fazendo da 'arte de bem fortificar' um negócio de Estado, já que os muros das fortalezas medievais não resistiam aos novos ataques.

Nesse contexto é que os tratados sobre fortificação foram multiplicados, a formação do engenheiro militar 'aclamada', e "a geometria e o desenho passaram a constituir uma forma privilegiada de transmissão de conhecimentos e de representação das coisas, além de um meio didático de reconhecido alcance prático" (SOROMENHO, 2001, p. 22). Além disso, segundo Valente (2007), ao final do século XVI e começo do século XVII ocorreu uma certa estabilidade e organização dos conteúdos dos tratados militares, de forma que as "questões eram abordadas segundo a ordem de conhecimentos úteis, partindose do mais abstrato: as matemáticas, depois o desenho, o manuseio de escalas, os diferentes tipos de fortificações" (p. 42). Pretendia-se, nas Academias Militares,

"formar engenheiros militares, cartógrafos e matemáticos, capazes de levar a cabo o levantamento de mapas com latitudes determinadas pelos novos métodos empregados na Inglaterra e na França, e habilitar engenheiros a construir fortificações para a defesa dos domínios ultramarinos." (VALENTE, 2007, p.46)

Dos tratados militares surgidos da 'arte da fortificação' nos séculos XVI e XVII é que o desenho posteriormente ganhará grande parte de seus conteúdos escolares. Isso porque será em especial da Academia Real Militar e da Academia dos Guarda-Marinha que virão professores militares e livros didáticos para o ensino nos preparatórios e liceus provinciais ${ }^{7}$. Com isso, ao longo do século XIX, após a independência do Brasil, o ensino

${ }^{7}$ Com a chegada da corte portuguesa ao país em 1808, o ensino sofreu significativas mudanças através da Academia Real dos Guarda Marinha, que veio junto com a corte, e da criação da Academia Real Militar em 1811, que substituiu a Real Academia de Artilharia, Fortificação e Desenho. "A academia destinava-se ao ensino das ciências exatas e da engenharia em geral, no sentido mais amplo da sua época, formando não só oficiais de engenharia e de artilharia, como também geógrafos e topógrafos que pudessem trabalhar em minas, caminho, portos, canais, pontes, fontes e calçadas. Para essa formação, os alunos teriam um curso completo de ciências matemáticas e aprenderiam física, química, mineralogia, metalurgia e história natural, além do aprendizado das 
de desenho foi gradativamente se deslocando ${ }^{8}$ do âmbito estrito da formação militar para a esfera pública, no bojo da criação das Escolas Normais (responsáveis por formar o professorado que atuaria na instrução primária); e dos Liceus Provinciais e do Colégio Pedro II, a partir de 1835 e 1837, respectivamente (ambos com vistas a garantir a formação de candidatos ao ensino superior). Os professores militares convocados para o ensino nessas novas instituições acabaram, assim, por difundir a escolarização técnico-militar desenvolvida nas Academias. A nova competência em construção de fortificações foi, portanto, fundamental para a criação da figura do engenheiro militar. Ademais, essa mesma competência configurou-se, a partir daí, em elemento base dessa formação profissional instituída, estando o saber em desenho a ela inextricavelmente entrelaçado, ganhando visibilidade e importância.

Mas, então, o que fez com que a 'necessidade de fortificar' tornasse-se premente ao longo e a partir do século XVI? Há, é verdade, uma estreita ligação com uma nova 'arte da guerra' despontada nesse período; contudo, a pergunta que permanece é: afinal, que feixe de problematizações deu as condições de possibilidade para a emergência de tal necessidade? E com ela, para a emergência do desenho enquanto um saber a ensinar? É a busca por esse feixe de problematizações que permite alguma compreensão sobre o processo de disciplinarização ${ }^{9}$ de práticas de desenhar. E, para tanto, a cartografia constituise em um (dentre tantos) rico território de análise, já que a elaboração e conhecimento de mapas para as construções arquitetônicas a serem empreendidas e para as análises dos locais a serem atingidos belicamente eram fortemente requeridos.

Daí que limitamos nosso campo de pesquisa a esse domínio, utilizando-o [a cartografia] estrategicamente como 'ponto de ataque', uma vez que nele as ligações entre desenho e sua disciplinarização são densas e numerosas. E porque há aí um emaranhado de interpositividades cujos limites e pontos de cruzamentos são bastante porosos; um território não de fronteiras fixadas, sob um efeito unificador, mas um potente multiplicador, que permite o trânsito por uma variedade de outros domínios. O que se apresenta a seguir é, pois, uma das problemáticas que constituem o referido feixe...

ciências militares. Os candidatos à Academia deveriam ter idade igual ou superior a 15 anos (VALENTE, 2007, p. 93).

${ }^{8}$ Em um complexo processo, tal como analisado em Machado (2016).

${ }^{9}$ Entenda-se disciplinarização no sentido de apropriação e ressignificação de práticas de desenhar que ganham o estatuto de conteúdo escolar. Em outras palavras, um processo de organização de um conjunto de enunciados "que tendem à coerência e à demonstratividade, que são recebidos, institucionalizados, transmitidos e às vezes ensinados como ciências" (FOUCAULT, 2009, p. 200). 


\section{Da disciplina do espaço}

As imagens...

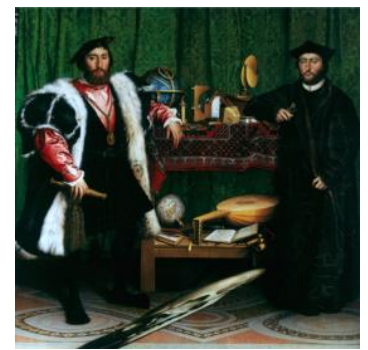

Figura 1: Hans Holbein. Os embaixadores. 1553

Fonte: Web Gallery of Art. Disponível em: <www.wga.hu>

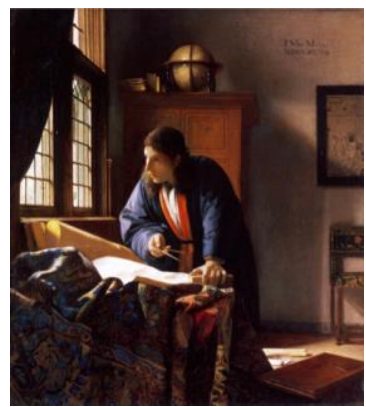

Figura 2: Johanes Vermeer. O geógrafo. 1668-1669.

Fonte: Web Gallery of Art. Disponível em: 〈www.wga.hu>

A primeira, do pintor alemão Hans Holbein (1497-1543); a segunda do pintor holandês Johanes Vermeer (1632-1675). Não se estenderá em uma análise descritiva ou interpretativa quer seja dos autores, de suas motivações, ou dos próprios elementos iconográficos dessas obras. O interesse aqui não está nos autores, ou em tais elementos, e sim no funcionamento dos enunciados que percebo aí circular. Ou ainda, para dizer de outra forma, o interesse está no que essas imagens podem provocar a pensar, afinal, toda imagem "nos oferece algo para pensar: ora um pedaço de real para roer, ora uma faísca de imaginário para sonhar" (SAMAIN, 2012, p. 22) ${ }^{10}$.

Têm-se aí, então, duas pinturas, dos séculos XVI e XVII, respectivamente. Em ambas, globos, mapas, e instrumentos geométricos ganham evidência. Globos, mapas, e instrumentos geométricos que convocam nosso pensamento, portanto. Disso, pode-se supor

${ }^{10}$ Particularmente, para a história da matemática e educação matemática, é esta a maneira metodológica com a qual se vem considerando o papel das imagens. Ver Flores (2015).

RBHM, Vol. 17, n 34, p. 49-71, 2017 
que práticas cartográficas figuravam entre as práticas sociais desse período histórico, a ponto de haver referência a elas em diversas pinturas, de diversos autores. E não somente porque percebemos nessas obras alguns elementos cartográficos, mas também porque muitas vezes eles são identificados com mapas e globos 'reais'. O mapa no quadro de Vermeer, por exemplo, é identificado com a "Carta náutica de todas as costas europeias", de Willem Blaeu, produzida no início do século XVII; o globo terrestre, por sua vez, é identificado como a segunda edição do globo de Jodocus Hondius, de 1618 (WELU, 1975, p. 543-544, tradução livre).

De fato, nesse período vê-se delinear o corte arqueológico que instaura o que se denomina "cartografia moderna"11. Corte que se situa, por sua vez, à época clássica: "o nome que se pode dar a um emaranhado de continuidades e descontinuidades, de modificações internas às positividades, de formações discursivas que aparecem e desaparecem" (FOUCAULT, 2009, p. 198). Período que funciona como um conjunto complexo e articulado de transformações que deixaram intactas um certo número de positividades, fixaram outras que ainda são as nossas, estabeleceram outras que se desfizeram e ainda se desfazem sob nossos olhos.

Isso não significa que esteja aí "o ponto de origem absoluta, ou de revolução total, a partir do qual tudo se organiza, tudo se torna possível e necessário, tudo se extingue para recomeçar" (FOUCAULT, 2009, p. 165). Tampouco que a partir desse momento e por um certo período haveria uma espécie de grande discurso, em que todos dissessem e pensassem as mesmas coisas, apesar das diferenças de superfície. É bem possível assinalar determinadas transformações quanto à produção de mapas no início do Renascimento, mas "o desaparecimento de uma positividade e a emergência de uma outra implica diversos tipos de transformações" (Ibidem, p. 194). Não uma substituição que troca tudo de lugar, descartando o velho e situando o novo de uma vez por todas, mas sim, uma transformação geral de relações que estabelece, ainda, fenômenos de continuidade, repetição e retorno.

Pois bem. A produção de mapas aumentou exponencialmente - tanto em quantidade quanto em qualidade - entre os séculos XV e XVII, saltando de mil a milhões nesse interstício de tempo (WOODWARD, 2007, p. 11). Isso está, obviamente, relacionado à invenção da imprensa em meados do século XV, mas também, e principalmente, (se não como causa e efeito, certamente como um paralelo e mutuamente dependente fenômeno) à 'descoberta' de inumeráveis novas terras decorrente das chamadas grandes navegações. Isso porque, segundo Schulz (1987, p. 87), por um lado, os cartógrafos ${ }^{12}$ passavam a empenhar-se em corrigir rapidamente as imagens cartográficas herdadas de outros tempos e a transmitir as novas descobertas em suas publicações; por outro, patronos e exploradores estavam cada vez mais impulsionados a financiar e empreender novas viagens por conta das contradições implícitas e dos 'vazios' explícitos observados nos mapas.

\footnotetext{
${ }^{11}$ Expressão utilizada para designar a prática cartográfica pós-renascentista, caracterizada pela construção de mapas com base em projeções matemáticas.

${ }^{12}$ Ressalte-se que este é um termo relativamente recente, datado de século XIX, quando da disciplinarização da geografia e da profissionalização do 'produtor de mapas', que então passou a ser chamado cartógrafo. Feita esta ressalva, este termo será livremente usado como equivalente da palavra inglesa mapmaker.
} 
Os mapas medievais (mappaemundi ${ }^{13}$ ) tornavam-se inadequados às novas necessidades impostas, de forma que transformações passaram a ser requeridas ${ }^{14}$. Em especial, novas soluções de modos de representação, tanto porque o mundo habitado encontrava-se consideravelmente expandido (em mais que o dobro do que era conhecido no período medieval), quanto, e sobretudo, porque à configuração sociocultural que se ia estabelecendo tornava-se fundamental estabelecer uma relação precisa entre as distintas localidades da terra.

É assim que uma nova positividade foi sendo estabelecida; não uma 'revolução', mas a formulação de novas respostas a novos problemas. Ora, é evidente que os mapas medievais não poderiam corresponder às demandas que se impunham; eles constituíam-se em mapas históricos, em narrativas; sua função principal nunca foi de localização espacial, como agora se requeria, mas sim "instruir os fiéis sobre os eventos significativos na história cristã ao invés de registrar suas localizações precisas" (WOODWARD, 1987, p. 286, tradução livre). É por isso que a emergência da cartografia moderna deve ser considerada como um 'acontecimento'. Acontecimento que tem na Renascença suas condições de possibilidade $^{15}$ e que se dá em um jogo de transformações que se estabelecem e estabelecem novas relações. Que não se configura, portanto, em uma mudança brusca de mentalidade, ou uma lenta maturação rumo ao progresso. Que não é:

"uma decisão, um tratado, um reino ou uma batalha, mas uma relação de forças que se inverte, um poder confiscado, um vocabulário retomado e voltado contra seus utilizadores, uma dominação que se enfraquece, se distende, se envenena e uma outra que faz sua entrada, mascarada.' (FOUCAULT, 1979, p. 28)

São três grandes categorias em que se pode enquadrar, segundo Woodward (2007, p. 12), as mudanças fundamentais que emergiram no campo cartográfico entre os séculos XV e XVI: mudanças internas quanto à estrutura dos mapas: sua lógica, linguagem e arranjo de seus elementos; mudanças na relação entre o mapa e o mundo observável,

\footnotetext{
${ }^{13}$ Woodward (1987, p. 296), classifica-os em quatro categorias: tripartido; zonal; quadripartido; e transicional. A categoria dos tripartidos inclui os mapas que representam o mundo habitado em três continentes, os chamados mapas T-O. Estes são os mapas mais usuais dentre o período medieval, possuindo uma forma circular com um $\mathrm{T}$ em seu interior. As partes do T são representadas pelas três principais vias navegáveis que os estudiosos medievais acreditavam dividir a Terra em três partes: Tanais (Rio Don), dividindo Europa e Ásia; Nilo dividindo África e Ásia; e o Mar Mediterrâneo dividindo Europa e África. Já na categoria zonal encontram-se os mapas representados por zonas latitudinais climáticas, ou climatas. A categoria dos quadripartidos compreende mapas intermediários entre as duas categorias anteriores, carregando características de ambas. Por fim, os mapas transicionais, tomam corpo nos séculos XIV e XV, antecipando de muitas formas aqueles característicos da renascença. Há influência aí das cartas portulanas, particularmente na representação do Mediterrâneo, bem como dos modelos de mundo Ptolomaico. Eles fiam-se, em certo grau, às explorações contemporâneas, especialmente às viagens portuguesas às ilhas atlânticas e à costa oeste da África. Ver anexo.

${ }^{14}$ Além dos mappaemundi (que buscavam dar a ver a porção conhecida do mundo habitado), durante a Idade Média circularam, de maneira geral, outros dois tipos de mapas: os portulanos, detalhadas cartas marítimas das costas do Mar Mediterrâneo, cujo objetivo era guiar os pilotos nas navegações; e mapas regionais topográficos ou itinerários.

${ }^{15}$ Para uma compreensão detalhada desta argumentação ver Machado (2016).
}

RBHM, Vol. 17, n 34, p. 49-71, 2017 
incluindo aí a quantificação e valorização da experiência, bem como um certo desapego à autoridade de textos geográficos clássicos, em função dos conflitos gerados pela observação direta do mundo; mudanças na relação entre mapas e sociedade por conta da disseminação de conhecimentos geográficos, provenientes, em grande parte, da invenção da imprensa e dos manuais produzidos por artesãos dedicados ao estudo de mapas.

Desse emaranhado de questões, talvez a principal seja o estabelecimento de uma nova concepção de espaço, colocada agora em termos abstratos. Ainda que no século XIII a obra de Roger Bacon, Opus Maius (1265), apresentasse indicativos de mapeamento por meio de um sistema de latitudes e longitudes ${ }^{16}$, há uma escassez de mapas terrestres (sobreviventes) construídos sob tal premissa nos séculos XIII e XIV. Essa característica - a utilização do sistema de coordenadas descrito pelo geógrafo alexandrino Cláudio Ptolomeu em sua obra Geographia, e utilizado para o mapeamento celeste desde o período helenístico - é percebida com força somente a partir do século XV. Nele, assume-se uma superfície isotrópica e uniforme em que posições abstratas podem ser plotadas, tanto em mapas gerais do mundo ou em mapas de alguma região específica.

Mas que não se entenda que está em Ptolomeu ou em sua obra os supostos méritos de demarcação de uma linha fronteiriça entre o regular e o original ou entre o velho e o novo. Claro que a tradução, na cidade italiana de Florença, em fins do século XV, do livro Geographia merece ser destacada. Contudo, atribuir a esse incidente as causas necessárias e suficientes para uma revolucionária matematização ou cientifização na construção de mapas (a emergência da chamada cartografia moderna) é, no mínimo, uma conclusão apressada, já que, conforme argumenta Dalché (2007, p. 285), a tradução e difusão desse trabalho deu-se em um contexto cultural e intelectual em que complexas e variadas motivações estavam em jogo. A tradução do Geographia foi um grande evento intelectual, mas foi um evento imerso em uma complexa história, envolvendo distintos meios intelectuais e distintos contextos culturais da Europa ${ }^{17}$.

\footnotetext{
${ }^{16}$ Paralelos e meridianos são círculos imaginários (horizontais e verticais, respectivamente), traçados no globo terrestre, que permitem obter a localização de qualquer ponto sobre sua superfície. O paralelo principal considerado é o equador, de maior círculo, (logo, situado na região central do globo), dividindo a Terra entre os hemisférios norte e sul. Em função da inclinação do eixo terrestre, somente sobre este paralelo os raios solares incidem sempre perpendicularmente, de forma que tomado como referência, lhe é atribuído zero graus. A partir dele, tomam-se círculos paralelos que alcançam no máximo 90 graus a norte ou a sul (os chamados pólos terrestres). A medida de latitude é a distância, ou seja, o ângulo formado (a partir do centro da Terra) por um ponto qualquer no globo em relação ao equador, sobre um mesmo meridiano. Os meridianos, por sua vez, são círculos que interceptam os pólos norte e sul. Por conta disto, não há um 'maior' meridiano, todos são 'círculos maiores' da esfera terrestre; portanto, com comprimentos equivalentes entre si e ao equador. Também por isto não há um meridiano central e a indicação do meridiano de referência é dada por escolhas arbitrárias. Atualmente, em nível mundial, utiliza-se o meridiano de Greenwich como referência; mas qualquer outro pode ser considerado o marco zero (Ptolomeu, por exemplo, utilizava o meridiano que passava pelas Ilhas Canárias). Uma vez escolhido, a medida de longitude é a distância, ou seja, o ângulo formado (a partir do centro da Terra) a leste ou a oeste (alcançando no máximo 180 graus em cada direção) entre um ponto qualquer na superfície em relação ao meridiano de referência, sobre um mesmo paralelo.

${ }^{17}$ Em algumas versões históricas presentes no campo da cartografia, concerne-se à 'redescoberta de Ptolomeu', no início do período renascentista, a 'pedra de toque' que desencadeou um sem precedente progresso cartográfico. Argumenta-se que antes de tal 'redescoberta' mapas eram construídos sobre fundamentos míticos, simbólicos, não científicos, ou simplesmente religiosos; e que, a partir de então, assumem uma feição 'moderna', sustentada em
} 
Além do que, parece não ter havido uma preocupação uníssona nos distintos meios intelectuais em que o Geographia circulou no início do período renascentista, bem como não foi propriamente o conteúdo cartográfico que primeiramente suscitou interesse em seu estudo. Mas sim, principalmente, sua relação com questões ligadas à astronomia e astrologia, o que, por sua vez, acabou levantando questionamentos históricos/filológicos em relação à tão admirada Antiguidade Clássica, ou de uma melhor compreensão da forma e tamanho do mundo habitado. Corrobora com isso o fato de que numerosos manuscritos da obra, em grande parte das maiores bibliotecas do mundo, contém apenas os textos dos livros que se voltam à listagem de nomes de lugares da antiguidade e toponímia, e não às explicações sobre projeção cartográfica.

Quando os florentinos atentaram para a comparação entre a imagem do mundo ptolomaica e aquela emergente dos ensinamentos de escritores latinos, discussões relativas a regiões longínquas do mundo, notavelmente a Etiópia, passaram a ganhar espaço nos círculos humanistas, motivados pelos encontros promovidos pelo Concílio de Florença ${ }^{18}$. Disso, expedições a terras distantes começaram a se fazer necessárias, então, quer para alguns, confirmar o insuperável modelo ptolomaico, quer para outros, usar seus mapas como meios de explorar um mundo ainda desconhecido. Tanto os novos aspectos quanto os erros encontrados na obra ptolomaica estimularam questionamentos e dúvidas quanto à geografia clássica e medieval, de forma que "as muitas contradições entre o mapa do mundo ptolomaico e o mappaemundi, então amplamente difundido, foram um estímulo intelectual para a exploração empírica", e consequentemente para as grandes navegações do século XV (DALCHÉ, 2007, p. 328, tradução livre). Isso atrelado, claro, a motivações políticas e econômicas, em especial, ao comércio de especiarias com o continente asiático. Tanto que o avanço português ao sul, ao longo da costa africana e daí em direção à Índia, junto à procura por ilhas do Atlântico e uma rota oeste para Ásia, reforçaram a necessidade de modernização dos mapas com dados atualizados.

As grandes navegações, por sua vez, foram um estímulo, entre o fim do século XV e início do século XVI, a uma nova recepção de Ptolomeu. Durante as expedições empreendidas por Colombo, por exemplo,

"dois procedimentos eram utilizados para registrar e interpretar as novas terras descobertas. Assim como seus sucessores, Colombo desenhava mapas, indubitavelmente construídos seguindo o método da cartografia marítima. Ele também toma medidas de latitude. Nas considerações da segunda viagem no "Libro copiador", ele dá uma descrição precisa do método seguido na produção do mapa enviado aos reis católicos com o intuito de fornecer alguma ideia da posição das novas ilhas descobertas. Este mapa foi construído a partir de meridianos e paralelos equidistantes, permitindo o cálculo de distâncias à maneira

um 'novo' conceito matematizado de espaço, representado por coordenadas cientificamente calculadas em uma rede de paralelos e meridianos. Tal perspectiva é percebida, para citar apenas um exemplo, em Crosby (1999).

${ }^{18}$ Reunião de bispos e outros membros pertencentes ao clero da igreja católica romana, iniciada em 1431 na cidade de Basiléia, transferida em 1438 para a cidade de Ferrara e então em 1439 para Florença.

RBHM, Vol. 17, n 34, p. 49-71, 2017 
de Ptolomeu, ou seja, considerando a relação entre graus de latitude e longitude." (DALCHÉ, 2007, p. 329, tradução livre)

Note-se que era possível desenhar mapas das costas marítimas sem qualquer preocupação com modos de representação, mas que, caso fosse necessário localizar tais costas em relação ao mundo conhecido era preciso recorrer ao método ptolomaico, independentemente dos erros de conteúdo geográfico presentes no Geographia. Também, para vastos espaços no oceano Atlântico, a cartografia marítima não era suficiente, necessitando sua integração em um sistema de projeção cartográfica e uma rede de paralelos e meridianos. A descoberta do 'novo mundo', portanto, começava a colocar novos problemas: "a localização das descobertas dentro da oikoumene ${ }^{19}$, o estabelecimento de uma relação precisa entre América e Ásia, e o exame dos efeitos das descobertas nos modos de representação" (DALCHÉ, 2007, p. 333, tradução livre).

Quanto ao Geographia, propriamente, interessante ressaltar que foi deliberadamente planejado como um manual para construção de mapas, constituindo-se em uma síntese e uma revisão dos trabalhos existentes, desde a antiguidade clássica grega até os contemporâneos de Ptolomeu. A obra inicia destacando a distinção entre geografia e corografia: esta, uma consideração apenas das partes do mundo habitado e não do todo; aquela, uma representação gráfica de toda a parte conhecida do mundo, juntamente com as coisas que nele ocorrem. Ao todo, o Geographia é composto por oito livros, distribuídos da seguinte maneira:

"Livro 1 - Introdução, incluindo projeções de mapas e crítica a Marino.

Livro 2 - Irlanda, Grã-Bretanha, Península Ibérica, Gália, Alemanha, províncias do Alto Danúbio, Dalmácia.

Livro 3 - Itália e ilhas adjacentes, Sarmatia na Europa, províncias mais baixas do Danúbio, Grécia e áreas adjacentes.

Livro 4 - Norte de África (oeste-leste), Egito, interior Líbia (África), Etiópia.

Livro 5 - Ásia Menor, Arménia, Chipre, Siria, Palestina, Arábia Petraea, Mesopotâmia, Arábia Deserta, Babilônia.

Livro 6 - Antigo império persa além de áreas já cobertas (oeste-leste); o Sacae e Scythia na fronteira com o império.

Livro 7 - Índia, Sinae, Taprobane, e áreas adjacentes. Resumo do mapa do mundo. Descrição da esfera armilar incluindo o mapa do mundo habitado. Resumo das secções regionais.

Livro 8 - Breve levantamento dos vinte e seis mapas regionais." (DILKE, 1987, p. 183, tradução livre)

Como se vê, a discussão acerca das projeções cartográficas está presente apenas no livro 1. A obra, quase em sua totalidade (dos livros 2 a 7), volta-se a uma detalhada apresentação da localização de regiões do mundo conhecido, incluindo cerca de $8 \mathrm{mil}$

${ }^{19}$ Termo grego que significa 'a porção conhecida do mundo'. 
cidades e lugares. Assim como procedeu no Almagesto $^{20}$, Ptolomeu recolheu nesse trabalho informações de vários de seus predecessores - especialmente o mais próximo, Marino de Tiro - organizando-as em uma sistemática tábua de coordenadas. Marino de Tiro, seu contemporâneo, empenhou-se na revisão de mapas existentes do mundo habitado, impulsionado pela expansão romana e consequente 'expansão do mundo'. Ptolomeu, então, valeu-se de muitos de seus esforços mas, ainda assim, a parte inicial do Geographia é reservada a uma meticulosa crítica do trabalho de Marino. Dessa crítica, emerge uma clara percepção de três grandes problemas relacionados à construção de mapas daquele período:

"O primeiro destes problemas, em um longa linhagem do trabalho grego, referia-se ao tamanho e posição do mundo habitado. (...).

Um segundo problema cartográfico em que Ptolomeu compartilhou um interesse com Marino - e de fato pode ter construído sobre os fundamentos por ele fornecidos - era o das projeções de mapas. (...).

Um terceiro e último problema nos mapas de Marino estava relacionado aos erros acumulados na compilação de detalhes geográficos provenientes de comentários escritos." (DILKE, 1987, p. 179-180, tradução livre)

Estabelecido o sistema de coordenadas geográficas, chega-se à complexa questão de transposição da esfera em uma superfície plana ${ }^{21}$. Ptolomeu examinou diferentes tipos de projeções, bem como sua eficácia em manter as características esféricas do globo quando representadas no plano. "Pode-se dizer que esta foi, talvez, sua maior contribuição para o desenvolvimento a longo prazo das bases matemáticas da cartografia" (DILKE, 1987, p. 185, tradução livre). Além disso, o geógrafo revelava uma clara percepção conceitual a respeito do problema fundamental de projeções de mapas:

"Cada um destes sistemas conceituais teria suas vantagens. O primeiro sistema, que plota o mapa em uma esfera, obviamente preserva a semelhança da forma do mundo e elimina a necessidade de qualquer manipulação; por outro lado, ele dificilmente fornece o tamanho necessário para conter todas as coisas que devem ser postas no espaço, tampouco permite que todo o mapa seja visto de um único ponto: ao invés disso, é preciso mover ou os próprios olhos ou a esfera para que se possa ver o restante.

O segundo sistema, representação em uma superfície plana, evita por completo as deficiências antes mencionadas. Mas lhe falta algum tipo de método que preserve a semelhança com a forma esférica de modo que se possa fazer as distâncias registradas na superfície plana tão

\footnotetext{
${ }^{20}$ Trabalho anterior ao Geographia que trata de questões astronômicas e cartografia celeste.

${ }^{21}$ O matemático alemão Carl Friedrich Gauss, trabalhando sobre projeções, demonstrou em 1820 que esta é de fato, uma tentativa sem sucesso. Uma esfera e um plano não são isométricos, ou seja, não é possível que tal transposição seja realizada, a uma escala constante, sem alguma distorção de forma ou angulação.
} 
proporcional quanto possível às verdadeiras distâncias." (PTOLOMEU, Geographia, apud DILKE, 1987, p. 185, tradução livre)

Quatro tipos de projeção de mapas foram detalhadamente expostos no trabalho. O primeiro é um sistema retangular, similar ao de Marino, cujos paralelos e meridianos são representados por linhas retas e ortogonais. Assumia-se aí que a escala ao longo do paralelo de Rhodes (o paralelo central do mundo conhecido à época) e ao longo de todos os meridianos fossem constantes. Marino assumia também que este paralelo media quatro quintos do comprimento do equador (logo, de qualquer meridiano). Esse método foi usado em alguns dos mapas regionais presentes nos textos finais do Geographia. Para mapas do mundo, entretanto, Ptolomeu o rejeitava, uma vez que o fato de os paralelos serem construídos com o mesmo comprimento causava grandes deformações em regiões distantes do paralelo central.

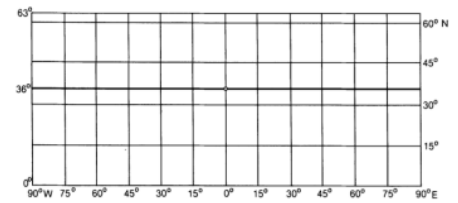

Figura 3: Projeção de Marino a partir da descrição de Ptolomeu. Fonte: Dilke (1987, p. 180).

Para superar essa desvantagem, Ptolomeu propôs um sistema, conhecido como sua 'primeira projeção', em que os meridianos são linhas retas a partir de um ponto imaginário além do pólo norte e os paralelos são arcos de um círculo de mesmo centro. Isso, pois os meridianos "podem dar a ilusão de linhas retas, quando, ao girar [o globo ou o olho] de um lado para o outro, cada meridiano fica diretamente em frente [ao olho], e seu plano passa pelo ápice do olhar". Em contrapartida, os paralelos "dão claramente a aparência de segmentos circulares que se arqueiam para o sul" (PTOLOMEU, Geographia, apud BROTTON, 2014, p. 49). Esse método não conseguia eliminar todas as distorções proporcionais ao longo dos paralelos, mas mantinha relações angulares consistentes em grande parte do mapa. Além disso, proporcionava uma escala constante ao longo do equador e dos meridianos, e uma correta proporção entre o comprimento do paralelo de Thule (o último ao norte) e o paralelo central.

"Uma vez que é impossível para todos os paralelos manter a proporção que há em uma esfera, será perfeitamente suficiente observar esta proporção no círculo paralelo que corre através de Thule e o equinocial, de maneira que os lados de nosso mapa que representam latitude sejam proporcionais aos verdadeiros e naturais lados da terra.

O paralelo passando por Rhodes deve ser inserido porque neste paralelo muitas provas de distâncias foram registradas, e inserido em uma correta 
relação com a circunferência de maior círculo, seguindo nisto Marino, que deu a razão para a circunferência do Equador (e dos meridianos) ao paralelo de Rhodes como 5:4. Ao fazer assim, nós devemos assegurar que a longitude de nossa terra, que é melhor conhecida, estará na correta proporção com a latitude." (PTOLOMEU, Geographia, apud DILKE, 1987, p. 186, tradução livre)

Nesse sistema são desenhados trinta e seis meridianos ao norte do equador e apenas um ao sul (este passando pelas regiões de Rhapta Promontory e Cattigara), separados cinco graus entre si. As localidades a serem marcadas no mapa deveriam ser feitas utilizando-se uma régua graduada, de comprimento igual ao raio do círculo usado para desenhar o equador. O cartógrafo deveria então fixá-la no ponto considerado o centro das curvas paralelas, girando-a de maneira a coincidir com algum meridiano, a partir das graduações em longitude inscritas no equador. Disso, usando as graduações em latitude inscritas na régua era facilmente possível marcas as cidades nos seus devidos lugares.

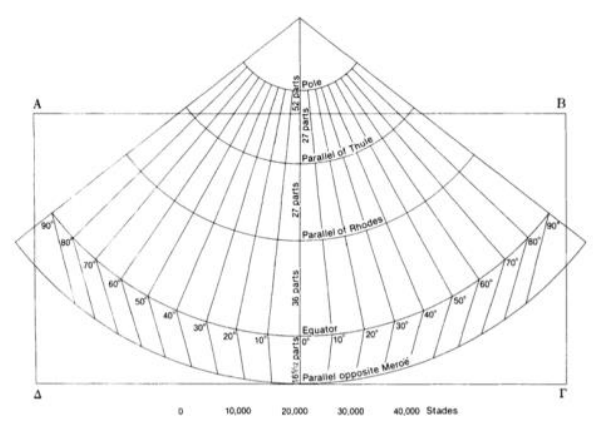

Figura 4: Primeira Projeção de Ptolomeu. Fonte: Dilke (1987, p. 187).

Ainda que esse sistema carregue vantagens em relação ao de Marino, alguns inconvenientes permanecem. Inicialmente, as porções norte e sul dos meridianos formam ângulos agudos no equador; segundo, as proporções dos paralelos entre Thule e o equador não são as mesmas da esfera. Os ângulos agudos no equador foram a solução encontrada por Ptolomeu para resolver o fato de que se sua projeção cônica fosse estendida para além desta linha, os paralelos a partir daí aumentariam de tamanho, o que em realidade não acontece no globo terrestre. Considerando-se o mundo conhecido de Ptolomeu, que se estendia a apenas 16 graus ao sul do equador, esse era apenas um pequeno inconveniente, mas é fácil imaginar que isso se tornaria um problema maior tanto mais ao sul fosse necessário estender o mapa. 
Nesse sentido é que a chamada 'segunda projeção' busca aliviar tais problemas, propondo um sistema com paralelos e meridianos curvos, cuja aparência assemelha-se àquela observada na esfera. $\mathrm{O}$ paralelo central do mapa deveria passar por Syene, ao norte do equador $23^{\circ} 50^{\prime}$. Ptolomeu advertia que a partir de um centro fora do painel retangular do mapa seria conveniente plotar os arcos representando os principais paralelos: Thule, Syene e Anti-Meroe. Além disso, os trinta e seis meridianos deveriam ser desenhados como arcos circulares, dezoito para cada lado do meridiano central em um intervalo de cinco graus. Os meridianos circulares eram possíveis devido à escolha de apenas três paralelos em que as verdadeiras proporções de distâncias eram conservadas ${ }^{22}$.

Mais uma vez, embora esse sistema apresentasse vantagens em relação aos anteriores, oferecendo uma melhor solução teórica, Ptolomeu advertia que a tarefa de desenhar um mapa através dele seria muito mais difícil. Pelo fato de os meridianos serem curvos, detalhes geográficos já não poderiam ser plotados com o uso de uma régua, tal como na primeira projeção.

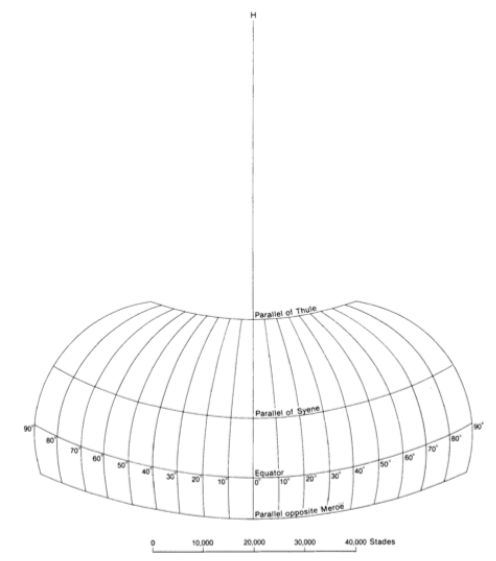

Figura 5: Segunda Projeção de Ptolomeu. Fonte: Dilke (1987, p. 187).

Por fim, a 'terceira projeção' ptolomaica surge de sua descrição da esfera $\operatorname{armilar}^{23}$ e parece não ter sido usada para construção prática de mapas, ao contrário das anteriores. "É razoável acrescentar aqui como o hemisfério em que o mundo habitado reside poderia ser representado em uma superfície plana, com o próprio hemisfério sendo rodeado por

${ }^{22}$ Comentadores tardios (Henricus Martellus Germanus parecendo ser o primeiro, em seu mapa do mundo de 1490) - descobriram que, na verdade, se os arcos nesta projeção não fossem circulares, todos os paralelos preservariam suas verdadeiras proporções.

${ }^{23}$ Esfera armilar é uma espécie de modelo reduzido do cosmos, com a terra ao centro, envolvida pelos anéis que compõem a esfera celeste. Estes anéis, em sua maioria, são projeções dos paralelos traçados no globo terrestre. Ver figura 7. 
uma esfera armilar...” (PTOLOMEU, Geographia, apud DILKE, 1987, p. 188, tradução livre).

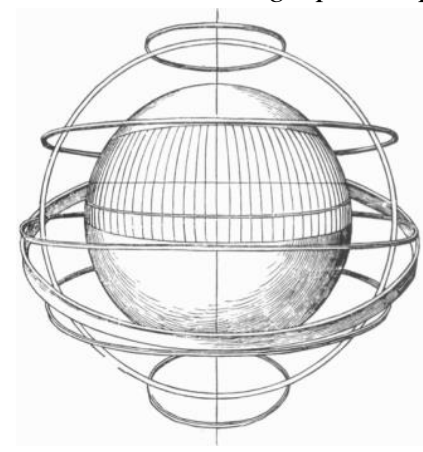

Figura 6: Terceira Projeção de Ptolomeu, vista pelo observador. Fonte: Dilke (1987, p. 188).

Nessa projeção, o observador é hipoteticamente situado fora dos anéis da esfera armilar imaginária, a uma distância em que o anel representando o trópico de verão celestial clareia o paralelo de Thule no globo, e o anel representando o equador celestial clareia o paralelo mais ao sul do mundo habitado (Anti-Meroe). O eixo visual é um plano horizontal que passa através de Syene.

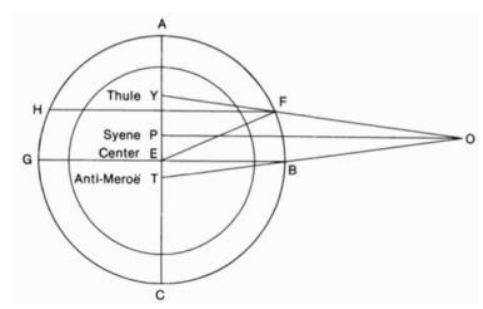

Figura 7: Diagrama da Terceira Projeção de Ptolomeu. Fonte: Dilke (1987, p. 188)

É esse o conteúdo matemático da obra ptolomaica. Não se sabe se o próprio Ptolomeu ou algum contemporâneo chegou a desenhar os mapas do Geographia, ou se eles foram adicionados somente em períodos posteriores, uma vez que não há qualquer mapa sobrevivente que possa ser remetido a esse período. Em todo caso, "em relação ao conteúdo geográfico dos mapas - em oposição à sua construção matemática - a parte mais importante 
do Geographia era aquela contendo as tábuas de coordenadas (livros 2-7)" (DILKE, 1987, p. 190, tradução livre). Nelas, algumas cidades são selecionadas e suas posições fornecidas em termos de latitude e longitude. Tais tábuas deveriam ser usadas tanto para mapas regionais quanto para mapas do mundo. São concebidos no trabalho vinte e seis mapas regionais: dez para Europa, quatro para África e doze para Ásia.

Ainda que Ptolomeu não deva ser considerado um marco rumo ao progresso, o fato é que gradativamente sistemas de projeções cartográficas foram sendo apropriados e utilizados na construção de mapas ${ }^{24}$. O que, como já destacado, remete a uma nova concepção de espaço, cujas implicações são substanciais:

"a posição de um lugar não é mais importante do que a de outro, e que tanto o centro geométrico quanto o enquadramento são construções arbitrárias resultantes das suposições sobre as linhas de referência em que longitudes e latitudes são medidas. A moldura ou completa o mapa ou é necessário estabelecer uma clara fronteira entre o espaço do mapa e o espaço exterior. A noção de um limitado espaço uniforme também implica que os objetos ali colocados são sincrônicos, um conceito que leva à ideia de que mapas históricos e 'modernos' poderiam e deveriam ser documentos separados. Uma vez que a superfície é representada como um espaço uniforme, escala e proporção são também possiveis. $O$ que também implica algum tipo de transformação geométrica do globo esférico para o mapa planificado. Além disso, o mapa agora não tem um ponto de vista único, mas múltiplos (estritamente falando, infinitos) pontos de vista com linhas de visão ortogonais (perpendicular ao plano)." (WOODWARD, 2007, p. 13, tradução livre)

Tais implicações acarretaram algumas vantagens. Se, diferentemente dos mapas medievais - em que, geralmente, Jerusalém ou Roma, ou qualquer outro lugar considerado sagrado, ocupava o centro do mundo - o sistema de projeções cartográficas, com suas graduações em latitude e longitude, impunham, isso sim, que a área a ser coberta pela projeção fosse cuidadosamente calculada, novos lugares, ainda desconhecidos, como aqueles explorados pelas grandes navegações, poderiam ser ali acrescentados a partir do conhecimento de suas coordenadas sem a necessidade de alongar ou estender o mapa. Além disso, a não adoção de um único ponto de vista (o princípio de ortogonalidade) permitia a visão completa de toda a superfície sem a necessidade de que o observador ou o mapa

\footnotetext{
${ }^{24}$ Foi-se estabelecendo o uso de rigorosas projeções matemáticas planas (ou azimutais), incluindo-se aí projeções ortográficas, estereográficas e gnomônicas (ou centrais). Basicamente, projeções planas são aquelas em que se transpõe a superfície do globo terrestre em uma superfície plana a partir de um determinado ponto de vista. Tais projeções são ditas ortográficas quando este ponto de vista está situado no 'infinito', sendo todos os raios de projeção paralelos entre si; são consideradas estereográficas quando o ponto de vista está situado em posição diametralmente oposta ao ponto de tangência do plano de projeção; por fim, diz-se que são gnomônicas (ou centrais) quando o ponto de vista está situado no centro da Terra. Além disso, são chamadas projeções polares se o plano de projeção for tangente a um dos polos; já se o plano de projeção for tangente a linha do equador, a projeção é chamada equatorial; e ainda, se o plano de projeção for tangente a um ponto qualquer, diz-se da projeção que é oblíqua. Ver anexo.
} 
fossem movidos. Por fim, esse sistema passava a prover um 'esquadrinhamento' do mundo através de paralelos e meridianos que lhe conferiam ordem e orientação sistematicamente calculadas.

\section{Dos rastros}

Novos ventos começavam a soprar... Que isso não seja entendido, entretanto, como uma 'evolução' no campo cartográfico. Mapas são construções que carregam distintos modos, marcados no tempo e no espaço, de culturas se relacionarem com esse mesmo tempo e espaço; todo mapa comporta determinado tipo de racionalidade (ou de lógica) tão compreensível no seu tempo quanto os mapas matematizados nos são hoje. Mapas não simplesmente reproduzem ou representam o mundo (ou uma região, ou o que quer que seja), eles o constroem. Dessa forma, com Brotton (2014), não se tratam de práticas cartográficas que seguiram um progresso inexorável em direção à precisão e objetividade científica, mas sim, de uma 'cartografia sem progresso'.

O globo mensurado. O mundo controlado. É uma 'disciplina do espaço' - agora dominado, ordenado, calculado, meticulosamente desenhado ${ }^{25}$ - que se instaura a partir de então. E o desenho, matematizado, nesse ínterim vai tornando-se um essencial instrumento de controle, produzindo novos efeitos de verdade e poder. De tudo isso, enfim, um fio do emaranho feixe de problematizações que deu as condições de possiblidade para a emergência do desenho enquanto disciplina escolar está posto. Fio que reforça a percepção de que os saberes (sejam eles escolares ou não) são, de fato, gerados em meio a práticas, experiências e questões que uma sociedade se impõe como verdades e normas sociais, políticas e culturais.

Pode-se viver sem norte, afinal? Ora, "não há nenhuma lei que diga que não se possa viver sem norte" (SARAMAGO, 1999, p. 296).

\section{Bibliografia}

BROTTON, J. 2014. Uma história do mundo em doze mapas. Rio de Janeiro: Zahar.

CHERVEL, A. 1990. História das disciplinas escolares: reflexões sobre um campo de pesquisa. Tradução de: LOURO, G. L. In: Teoria e Educação, Porto Alegre, n. 2, p. 177-229.

CROSBY, A. W. 1999. A mensuração da realidade: a quantificação e a sociedade ocidental (1250-1600). Tradução de Vera Ribeiro. São Paulo: Ed. da UNESP.

DALCHÉ, P. G. 2007. The Reception of Ptolemy's Geography (End of the Fourteenth to Beginning of the Sixteenth Century). In: HARLEY, J.; WOODWARD, D. (org.). The History of Cartography, vol. III, Chicago, The Chicago University Press, p. 285-364.

\footnotetext{
${ }^{25}$ Para uma discussão acerca de como o espaço passou a ser medido, calculado, padronizado e representado no Renascimento, através da técnica da perspectiva central, desenvolvida no período por Leon Batista Alberti, especialmente, ver Flores $(2003,2007)$.
}

RBHM, Vol. 17, n 34, p. 49-71, 2017 
DILKE, O. A. W. 1987. The Culmination of Greek Cartography in Ptolemy. In: HARLEY, J.; WOODWARD, D. (org.). The History of Cartography, vol. I, Chicago, The Chicago University Press, p. 177-200.

FLORES, C. R. 2007. Olhar, saber, representar: sobre a representação em perspectiva. São Paulo: Musa Editora.

FLORES, C. R. 2015. Imagem. In: VALENTE, W. R. Cadernos de Trabalho, v. 9.

FOUCAULT, M. 1979. Microfísica do Poder. MACHADO, R. (Org.). Rio de Janeiro: Edições Graal.

FOUCAULT, M. 2009 (7 ed.). A Arqueologia do Saber. Rio de Janeiro: Forense Universitária. FOUCAULT, M. 2013. A verdade e as formas jurídicas. Rio de Janeiro: Nau.

JOLY, F. 1990 (5ª ed.). A Cartografia. São Paulo: Ed. Papirus.

MACHADO, R. B. 2016. Cartografia, Saber, Poder: Da emergência do desenho como disciplina escolar. Tese (Doutorado em Educação Científica e Tecnológica), Universidade Federal de Santa Catarina, Florianópolis, SC, Brasil.

MACHADO, R. B.; FLORES, C. R. 2016. Entre práticas [historiográficas e de desenho]: um movimento metodológico de pesquisa. In: Zetetiké, Campinas, SP, v.24, n.2, p.237-248

MACHADO, R. B.; FLORES, C. R. 2016a. Considerações Intempestivas sobre um fazer História [da Educação Matemática]. In: REVEMAT, Florianópolis (SC), v.11, Ed. Filosofia da Educação Matemática, p. 149-161.

MIGUEL, A. 2010. Percursos Indisciplinares na Atividade de Pesquisa em História (da Educação Matemática): entre jogos discursivos como práticas e práticas como jogos discursivos. In: BOLEMA, Rio Claro, v. 23, n. 35A.

PTOLEMY, C. 1966. Geographia. 3 vols. Edited by C.F. A. Nobbe. Leipzig: C. Tauchnitz, 1843-45; reprinted in one volume with an introduction by Aubrey Diller, Hildesheim: Georg alms.

SAMAIN, E. 2012. As imagens não são bolas de sinuca. Como as imagens pensam. In: SAMAIN, E. (org.). Como pensam as imagens, Campinas, SP: Ed. da Unicamp.

SARAMAGO, José. 1999. A jangada de pedra. São Paulo: Companhia das Letras.

SCHULZ, J. 1987. Maps as Metaphors: Mural Map Cycles of the Italian Renaissance. In:

SOROMENHO, M. 2001. Descrever, registrar, instruir: práticas e usos do desenho. In: A ciência do desenho: a Ilustração na colecção de códigos da Biblioteca Nacional. Lisboa: Ministério da Cultura; Biblioteca Nacional.

VALENTE, W. R. 2007 (2. ed.). Uma história da matemática escolar no Brasil: 1730-1930. São Paulo: Annablume.

WOODWARD, D. (org). Art and Cartography: Six Historical Essays, Chicago, The Chicago University Press, p. 97-122.

SNYDER, J. P. 2007. Map Projections in the Renaissance. In: HARLEY, J.; WOODWARD, D. (org.). The History of Cartography, vol. III, Chicago, The Chicago University Press, p. 365-381. WELU, J. 1975. Vermeer: His cartographic sources. In: Art Bulletin, v. 57, p. 529-547, WOODWARD, D. 1987. Medieval Mappaemundi. In: HARLEY, J.; WOODWARD, D. (org.). The History of Cartography, vol. I, Chicago, The Chicago University Press, p. 286-370.

WOODWARD, D. 2007. Cartography and the Renaissance: Continuity and Change. In: HARLEY, J.; WOODWARD, D. (org.). The History of Cartography, vol. III, Chicago, The Chicago University Press, p. 3-24. 
Rosilene Beatriz Machado

Departamento de Metodologia de Ensino - MEN campus de Florianópolis - Brasil

E-mail: rosilene.machado@ufsc.br

\section{Cláudia Regina Flores}

Departamento de Metodologia de Ensino - MEN campus de Florianópolis - Brasil

E-mail: claudia.flores@ufsc.br 
ANEXO

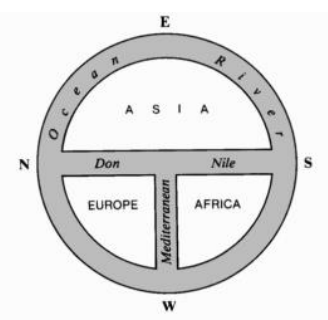

Figura 8: Mappaemundi tripartido - T-O.

Fonte: Woodward (1987, p. 297)

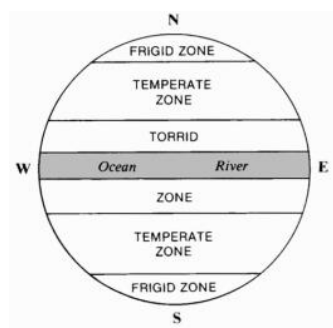

Figura 9: Mappaemundi zonal. Fonte: Woodward (1987, p. 297).

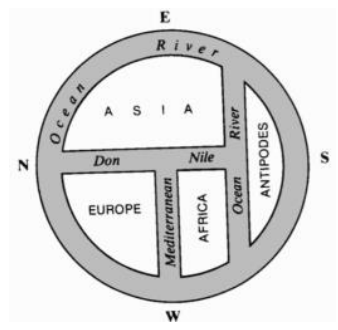

Figura 10: Mappaemundi quadripartido. Fonte: Woodward (1987, p. 297). 


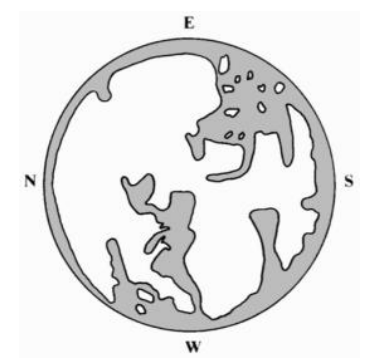

Figura 11: Mappaemundi transicional. Fonte: Woodward (1987, p. 297).

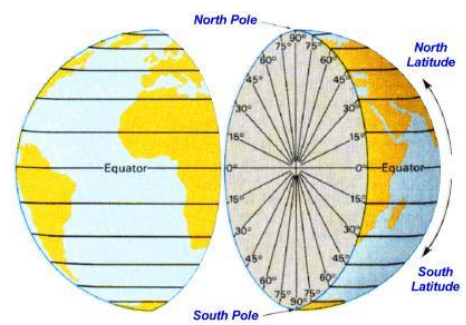

Figura 12: Paralelos de latitude. Fonte: http://geographyworldonline.com/tutorial/lesson1.html

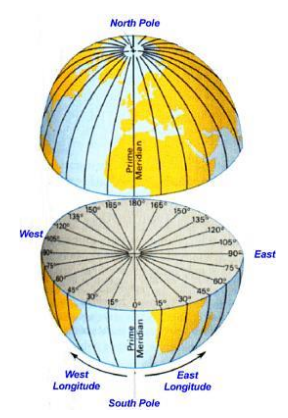

Figura 13: Meridianos de longitude.

Fonte: http://geographyworldonline.com/tutorial/lesson1.html

RBHM, Vol. 17, no 34, p. 49-71, 2017 


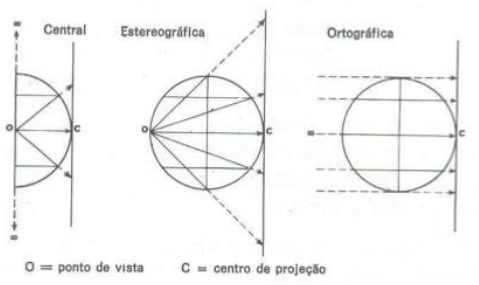

Figura 14: Tipos de projeção plana. Fonte: Joly (1990, p. 49).

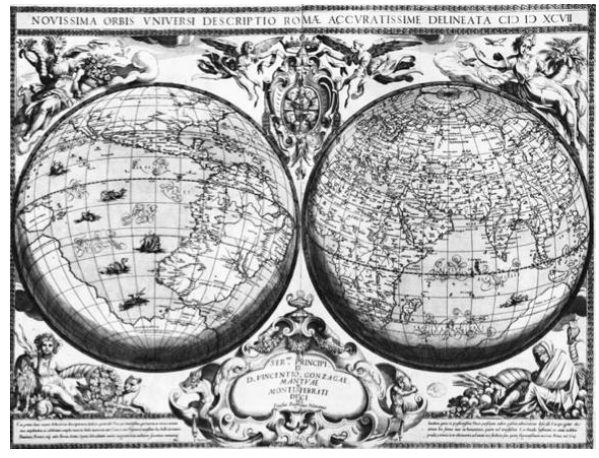

Figura 15: Exemplo de mapa de projeção ortogonal. Mapa do mundo de Fausto Rughesi, 1597. Fonte: Snyder (2007, p. 369).

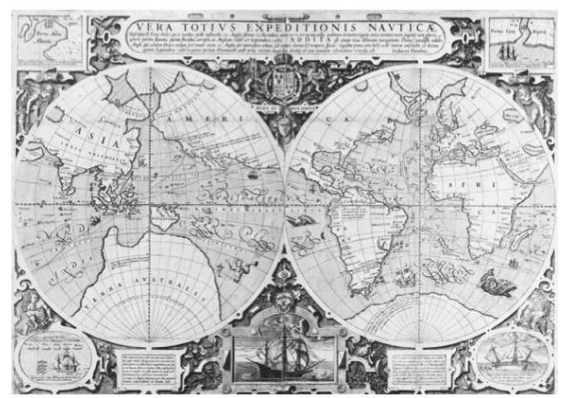

Figura 16: Exemplo de mapa de projeção estereográfica. Mapa do mundo de Jodocus Hondius, 1595. Fonte: Snyder (2007, p. 372). 


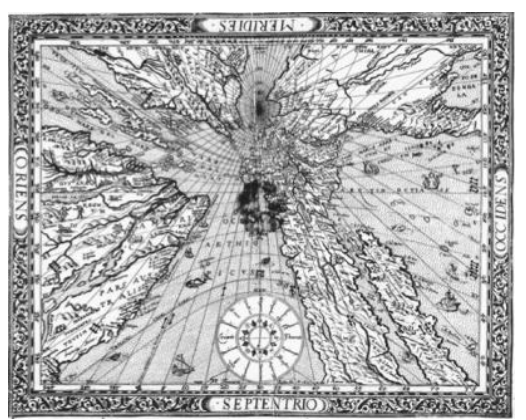

Figura 17: Exemplo de mapa de projeção gnomônica. Mapa do mundo de Franz Ritter, 1610. Fonte: Snyder (2007, p. 379). 